\title{
Morfofisiologia e valor nutritivo do capim-braquiária em sistema silvipastoril com diferentes arranjos espaciais ${ }^{1}$
}

\section{Morphophysiology and nutritive value of signalgrass in silvipastoral system with different tree arrangements}

\author{
Joysiene Sanguinete Coelho²; Saulo Alberto do Carmo Araújo ${ }^{3 *}$; \\ Maria Celuta Machado Viana ${ }^{4}$; Severino Delmar Junqueira Villela3; \\ Francisco Morel Freire ${ }^{4}$; Thiago Gomes dos Santos Braz ${ }^{3}$
}

\section{Resumo}

\begin{abstract}
Objetivou-se com este trabalho avaliar o efeito dos arranjos espaciais no valor nutritivo, produtividade e estrutura do sub-bosque de capim-braquiária em sistema silvipastoril com diferentes tempos de rebrotação $(35,42,49,56$ e 63$)$. O delineamento foi em blocos casualizados com três repetições em esquema fatorial com parcelas subdivididas $2 \times 2 \times 5$, onde avaliaram-se dois arranjos espaciais [linhas duplas $9 \times(2 \times 2 \mathrm{~m})$ e linha simples $(9 \times 2 \mathrm{~m})$ ] e dois locais de amostragem (no centro da entrelinha e sob a copa das árvores) na parcela e cinco tempos de rebrotação $(35,42,49,56$ e 63 dias) nas subparcelas. Utilizou-se sistema silvipastoril implantado em junho de 2008, em área de pastagem degradada com predominância de Brachiaria decumbens. $\mathrm{O}$ pasto foi uniformizado a $15 \mathrm{~cm}$ do nível do solo por meio de pastejo. Foram avaliadas a produção de massa seca, relação lâmina colmo, interceptação luminosa e índice de área foliar. Além destas avaliaram-se também as características de valor nutritivo teor de matéria seca, fibra em detergente neutro e ácido, proteína bruta e lignina. Foi realizado o monitoramento da radiação fotossinteticamente utilizando o ceptômetro. $\mathrm{O}$ uso de arranjos com linhas simples ou duplas não influenciou o índice de área foliar, a interceptação luminosa e a produção de massa seca. A relação lâmina:colmo foi influenciada pelo local de amostragem somente no arranjo duplo. Os teores de fibra em detergente neutro foram substancialmente maiores no arranjo duplo. Portanto, o uso de linhas duplas de eucalipto implica em redução na quantidade de radiação incidente no sub-bosque, mas não implica em redução da produtividade do pasto em relação ao arranjo simples. Estes resultados indicam que o uso de arranjos duplos pode permitir a colheita de maior quantidade de árvores sem prejudicar a produtividade do pasto.
\end{abstract}

Palavras-chave: Brachiaria decumbens, espaçamento, eucalipto, interceptação luminosa, pastagem, sombreamento

\footnotetext{
Abstract

The study was carried out with the aim to evaluate the effect of different tree arrangements in forage yield, nutritive value and structure of the understory of signalgrass (Brachiaria decumbens) in silvipastoral system with different regrowth times. The design was in complete randomized block with tree replicates in a factorial

${ }^{1}$ Parte da dissertação do primeiro autor, Universidade Federal dos Vales do Jequitinhonha e Mucuri, UFVJM, Diamantina, MG.

${ }^{2}$ Discente do Curso de Mestrado do Programa de Pós-graduação em Zootecnia, UFVJM, Diamantina, MG. E-mail: josy_zoo@ hotmail.com

${ }^{3}$ Profs. Adjuntos do Dept ${ }^{0}$ de Zootecnia, UFVJM, Diamantina, MG. E-mail: saulo.araujo@ufvjm.edu.br; svillela@ufvjm.edu.br; thiagogsbz@hotmail.com

${ }^{4}$ Pesquisadores da Empresa de Pesquisa Agropecuária de Minas Gerais, EPAMIG Centro Oeste, Fazenda Experimental Santa Rita, Prudente de Morais, MG. E-mail: mcv@epamig.br; francisco.morel@epamig.br

* Autor para correspondência
} 
scheme with split-plots $2 \times 2 \times 5$ consisting two spatial arrangements [Double lines $9 \times(2 \times 2 \mathrm{~m})$ and simple lines $(9 \times 2 \mathrm{~m})$ ] in two sampling places (in the middle of the intercropping and under the three canopy) in the plot and five regrowth times $(35,42,49,56$ e 63 days) in the split-plot. It was used a silvipastoral system established since June, 2008 in degraded pasture with signalgrass predominance. The pasture was homogenized by grazing at $15 \mathrm{~cm}$ from the soil level. Were evaluated the dry matter yield leaf:stem ratio, light interception and leaf area index. In addition were evaluated the nutritive value characteristics dry matter content, neutral and acid detergent fiber, crude protein and lignin. The photosynthetic active radiation was monitored. The use of simple or double lines did not influence the leaf area index, light interception and dry mass yield. The leaf:stem ratio was influenced by the sampling place only in the double line arrangement. The neutral detergent fiber was substantially high in the double line arrangement. Therefore, the use of double lines reduces the photosynthetic active radiation amount incident in the understory, but does not reduce the forage yield in relation to simple line arrangements. These results indicate the use of double lines arrangement may allow the harvest of more threes without reduce the pasture production.

Key words: Brachiaria decumbens, eucalyptus, light interception, pasture, spacing, shading

\section{Introdução}

A bovinocultura é um dos principais segmentos da atividade agropecuária brasileira e possui grande potencial para expansão. De acordo com levantamentos recentes, estima-se que o país seja o maior exportador de carne bovina e o sexto maior produtor de leite (FAO, 2010), com um rebanho de cerca de 211 milhões de cabeças (IBGE, 2012) criadas basicamente em pastagens. Apesar da relevância destes números, acredita-se que boa parte das áreas em pastagens esteja degradada ou em processo de degradação.

Dentre as estratégias de recuperação de áreas degradadas encontram-se os sistemas silvipastoris (SSPs), que podem ser definidos como uma modalidade dos sistemas agroflorestais onde há integração do componente arbóreo, plantas forrageiras e animais, na mesma área (BERNARDINO; GARCIA, 2009). O potencial para recuperação se deve a melhorias de características do solo como maior cobertura, ciclagem de nutrientes e teor de matéria orgânica. Como benefícios para o sistema de produção também podem ser citados a melhoria do valor nutritivo do pasto (PACIULLO et al., 2007), das condições microclimáticas para humanos e animais e a diversificação da renda dos produtores.

A produtividade do pasto no SSP é influenciada pela quantidade de radiação fotossinteticamente ativa (RFA) que penetra no sub-bosque (SOARES et al., 2009), que, por sua vez, é determinada pelo espaçamento utilizado. Assim, durante o planejamento do sistema, se deve optar por arranjos espaciais que proporcionem níveis adequados de RFA para a produção forrageira. Segundo Paciullo et al. (2007), os dois principais tipos de arranjo são o de linha simples ou linhas duplas, sendo que o espaçamento entre as árvores dentro das linhas ou entre as linhas pode variar de acordo com os objetivos do sistema.

Provavelmente, em sistemas mais adensados, a quantidade de luz interceptada pela copa das árvores restringe o potencial de interceptação pelas forrageiras que respondem a esta limitação por meio de mudanças nas características estruturais para se tornarem mais eficientes em ambientes com luminosidade limitada. Em sombreamento natural, Paciullo et al., (2007) observaram que níveis de até $35 \%$ de sombra pouco modificaram a produtividade da pastagem em relação ao sol pleno. No entanto, são necessários mais estudos, não apenas para quantificar a radiação incidente no sub-bosque, mas também para avaliar o percentual desta radiação que é interceptado pelos componentes do sistema.

Assim objetivou-se com este trabalho quantificar a radiação incidente no sistema e sua influência sobre a produção, estrutura e valor nutritivo do 
capim-braquiária em sistema silvipastoril com dois arranjos espaciais.

\section{Material e Métodos}

O experimento foi conduzido na Fazenda Experimental de Santa Rita (FESR) pertencente à EPAMIG. A FESR localiza-se no município de Prudente de Morais, Minas Gerais, a $732 \mathrm{~m}$ de altitude, nas coordenadas geográficas 19²7'15" S e 4409'11', W. O clima da região, segundo classificação de Köppen, é do tipo Aw, com estações seca e chuvosa bem definidas ocorrendo, respectivamente nos meses de maio a outubro e de novembro a abril. Durante o experimento, dados climáticos foram registrados (Tabela 1).

O delineamento experimental foi em blocos ao acaso com duas repetições em esquema fatorial com parcelas subdivididas $2 \times 2 \times 5$, onde avaliaram-se dois arranjos espaciais [linhas duplas $9 \times(2 \times 2 \mathrm{~m})$, e linha simples $(9 \times 2 \mathrm{~m})$ ] e dois locais de amostragem (no centro da entrelinha e sob a copa das árvores) na parcela e cinco intervalos de corte $(35,42,49,56$ e 63 dias) nas subparcelas.

Tabela 1. Precipitação pluviométrica (pp) normal climatológica (1960-2010) e mensal, e temperaturas máxima (Tmáx) e mínima (Tmín) em durante o período experimental.

\begin{tabular}{ccccc}
\hline Meses do ano & $* *$ Normais - pp $(\mathrm{mm})$ & *Precipitação mensal $(\mathrm{mm})$ & $* *$ Tmax $\left({ }^{\circ} \mathrm{C}\right)$ & $* *$ Tmín $\left({ }^{\circ} \mathrm{C}\right)$ \\
\hline Março/2011 & 41,49 & 0 & 29,3 & 19,3 \\
Abril/2011 & 59,19 & 15,3 & 29,3 & 17,9 \\
Maio/2011 & 7,32 & 0 & 28,2 & 17,9 \\
\hline
\end{tabular}

Fonte: Elaboração pelos autores com base em dados da *Estação meteorológica da Fazenda Experimental Santa Rita e da **Estação meteorológica da Embrapa Milho e Sorgo.

O sistema silvipastoril foi implantado em 2008 em área de pastagem degradada com predominância de Brachiaria decumbens, formada há aproximadamente 15 anos. O solo, classificado como Latossolo Vermelho-Amarelo distrófico, é textura argilosa (EMBRAPA, 2006). Amostras deste solo foram coletadas e analisadas quanto as suas características físicas e químicas nas profundidades de 0 a 20 e 20 a $40 \mathrm{~cm}$ (Tabela 2).

Tabela 2. Características químicas e físicas das amostras de solo da área experimental coletadas nas profundidades de $0-20$ e $20-40 \mathrm{~cm}$

\begin{tabular}{ccccccccccccc}
\hline $\begin{array}{c}\text { Prof. } \\
(\mathrm{cm})\end{array}$ & $\mathrm{pH}^{1}$ & $\mathrm{H}+\mathrm{Al}^{2}$ & $\mathrm{Al}^{3}$ & $\mathrm{Ca}^{3}$ & $\mathrm{Mg}^{3}$ & $\mathrm{~K}^{4}$ & $\mathrm{P}^{4}$ & $\mathrm{MO}^{5}$ & $\begin{array}{c}\text { Areia } \\
\text { Grossa }\end{array}$ & $\begin{array}{c}\text { Areia } \\
\text { Fina }\end{array}$ & Silte & Argila \\
\hline $0-20$ & 5,4 & 7,5 & 0,2 & 3,2 & 0,7 & 70,3 & 3,7 & 4,3 & 1 & 19 & 13 & 67 \\
$20-40$ & 5,3 & 7,6 & 0,6 & 2,5 & 0,5 & 56,7 & 3,7 & 4,0 & 1 & 19 & 11 & 69 \\
\hline
\end{tabular}

${ }^{1}$ Potencial hidrogeniônico em água, relação $1: 2,5 ;{ }^{2}$ Acidez trocável em extrator $\mathrm{Ca}\left(\mathrm{OA}_{\mathrm{c}}\right)_{2} \mathrm{~mol} \mathrm{~L} \mathrm{~L}^{-1} \mathrm{pH} 7,0 ;{ }^{3} \mathrm{Alumínio} \mathrm{trocável,} \mathrm{cálcio}$ e magnésio em extrator KCL $1 \mathrm{~mol} \mathrm{~L}{ }^{-1}$; ${ }^{4}$ Potássio e fósforo em extrator Mehlich-1; ${ }^{5}$ Matéria orgânica.

Fonte: Elaboração dos autores.

Para implantação do sistema, foram utilizados Eucalyptus urophylla), plantados no período de 11 clones de eucalipto I144 (Eucalyptus grandis x a 17 de junho de 2008, com sentido predominante 
leste-oeste. No arranjo $9 \times(2 \times 2 \mathrm{~m})$ o número médio de árvores por hectare foi de 909 , enquanto no arranjo $9 \times 2 \mathrm{~m}$, o número médio foi de 556 árvores por hectare.

No primeiro ano após a implantação do sistema foram realizados a limpeza da área experimental, o controle de formigas, a dessecação de toda a cobertura vegetal e a aplicação de 2 t/ha de calcário dolomítico. Realizou-se o preparo convencional do solo por meio de uma aração e duas gradagens. A subsolagem foi feita nas linhas de plantio do eucalipto, com aplicação de $400 \mathrm{~kg} / \mathrm{ha}$ de fosfato natural reativo.

A adubação de plantio consistiu da aplicação de $150 \mathrm{~g} /$ cova de adubo formulado NPK 10-28-06 + $0,3 \%$ Boro (B) $+0,5 \%$ de Zinco ( $\mathrm{Zn}$ ). O plantio das mudas de eucalipto foi realizado utilizando-se gel hidratado e realizou-se irrigação com 4 litros de água por planta duas vezes por semana até o completo pegamento. No início do período chuvoso, as plantas receberam adubação de cobertura com $150 \mathrm{~g} /$ planta da formulação 20-00-20. Procedeuse o controle da forrageira ao redor das mudas por meio de capinas. Em setembro de 2009 foi feita primeira desrama e em março de 2010, a segunda.

Em novembro de 2009 foi realizado o plantio do capim-braquiária (Brachiaria decumbens cultivar Basilisk) utilizando $10 \mathrm{~kg} / \mathrm{ha}$ de semente. A forrageira foi estabelecida em integração com o milho há uma distância mínima de $1,5 \mathrm{~m}$ da linha de eucalipto.

Para a uniformização do pasto, utilizou-se alta taxa de lotação em curto período de tempo, de modo que 47 animais, bovinos mestiços (Holandes x Zebu) machos castrados, com peso médio de 400 $\mathrm{kg}$, foram alocados na área no período de três a nove de março de 2011, quando o pasto atingiu a altura média de $15 \mathrm{~cm}$.

As avaliações foram iniciadas quando o sistema possuía dois anos e nove meses após estabelecimento. A primeira amostragem do capimbraquiária e medições da interceptação luminosa foram realizadas com 35 dias de rebrotação e as demais coletas foram realizadas em intervalos semanais, totalizando cinco amostragens.

O monitoramento da interceptação de luz pelas plantas de eucalipto e pela forrageira no subbosque foi realizado utilizando-se dois aparelhos analisadores de dossel (Ceptômetro AccuPAR modelo - LP 80), que também permitiram estimar o índice de área foliar (IAF) do dossel forrageiro. O equipamento é constituído por dois sensores, um manual em forma de barra e outro externo, que permitem medições simultâneas da radiação fotossinteticamente ativa (RFA em $\mu \mathrm{mol} \mathrm{m} \mathrm{m}^{-2} \mathrm{~s}^{-1}$ ) acima e abaixo do dossel. O sensor externo foi posicionado a $70 \mathrm{~cm}$ de altura.

Leituras simultâneas das parcelas do SSP e da pastagem convencional foram tomadas, em dias de coleta com céu aberto, a cada 1 minuto durante o período de 11:00 às 13:00 horas. Por meio destas foi descrita a quantidade de radiação incidente no pasto em sol pleno e no pasto em sub-bosque de SSP. Ao se realizar medidas acima e abaixo de ambos dosséis, estimou-se também a sua interceptação de luz.

Antes de cada corte, a altura do dossel forrageiro foi medida em cinco pontos de cada parcela e em cada local para determinação da altura média do pasto, que foi medida desde o solo até a curvatura das folhas. Em cada corte, tomaram-se amostras em dois locais, no centro da entrelinha e sob a copa das árvores há $1,5 \mathrm{~m}$ de distância de suas bases. Foram coletadas duas amostras por local, sendo uma a $15 \mathrm{~cm}$ do nível do solo para determinação da produção de massa seca (PMS) e outra rente ao solo para determinação da composição morfológica da forragem nos diferentes tempos de rebrotação. Ambas foram realizadas com auxílio de cutelo e quadro de $1 \mathrm{~m}^{2}$.

As amostras retiradas rente ao solo foram separadas manualmente em seus componentes morfológicos lâmina foliar e colmo (colmo verdadeiro + bainha foliar) e, posteriormente, secas 
em estufa de ventilação forçada a $65^{\circ} \mathrm{C}$ e pesadas. A relação lâmina foliar:colmo (RLC) foi estimada por meio da razão entre a massa seca de lâminas foliares e de colmos. Já as amostras coletadas a 15 cm do nível do solo foram desidratadas e moídas em moinho tipo Willey com peneira de $1 \mathrm{~mm}$, para determinação da composição bromatológica. Foram determinados os teores de matéria seca (MS), proteína bruta $(\mathrm{PB})$, fibra em detergente neutro (FDN), fibra em detergente ácido (FDA), teor de proteína bruta $(\mathrm{PB})$ e lignina em ácido sulfúrico (LAS) conforme Silva e Queiroz (2002).

Os dados foram submetidos à análise de variância e as médias foram testadas por meio do teste Tukey, adotando-se 10\% como nível crítico de probabilidade para o erro do tipo I. Os dados relativos ao tempo de rebrotação foram submetidos à análise de regressão. Todas as análises foram realizadas por meio do pacote estatístico computacional SISVAR, versão 4.2 (FERREIRA, 2008). Os dados coletados em sol pleno foram comparados de forma descritiva aos dados coletados no sistema silvipastoril.

\section{Resultados e Discussão}

Não observou-se efeito de arranjo, local e tempo de rebrotação sobre a produção de massa seca (PMS), interceptação luminosa do pasto (IL) e índice de área folair (IAF) (Tabela 3). Nota-se que os pastos não atingiram os $95 \%$ de IL, que é o momento recomendado para a colheita da forragem em sistemas rotativos.

Tabela 3. Produtividade média de massa seca (PMS) (t/ha), interceptação luminosa (IL) (\%) e índice de área foliar (IAF) do dossel forrageiro em dois arranjos de eucalipto e dois locais de amostragem.

\begin{tabular}{lccccr}
\hline \multirow{2}{*}{ Variáveis } & \multicolumn{2}{c}{ Arranjos de eucalipto } & \multicolumn{2}{c}{ Local de amostragem } & \multirow{2}{*}{ Média } \\
\cline { 2 - 5 } & Linha dupla & Linha simples & Na entrelinha & Sob copa & \\
\hline PMS (t/ha) & $0,44 \mathrm{a}$ & $0,44 \mathrm{a}$ & $0,45 \mathrm{a}$ & $0,44 \mathrm{a}$ & 0,44 \\
IL(\%) & $49,00 \mathrm{a}$ & $51,00 \mathrm{a}$ & $47,00 \mathrm{a}$ & $52,00 \mathrm{a}$ & 49,50 \\
IAF & $0,98 \mathrm{a}$ & $1,00 \mathrm{a}$ & $1,03 \mathrm{a}$ & $0,96 \mathrm{a}$ & 0,99 \\
\hline
\end{tabular}

Médias seguidas de letras diferentes na linha são significativas pelo teste de Tukey* $(\mathrm{P}<0,05)$.

Fonte: Elaboração dos autores.

No sistema em sol pleno (monocultivo de Brachiaria decumbens.cv Basilisk) a PMS do período experimental foi de apenas 0,54 t/ ha. Contudo, por meio do monitoramento das condições climáticas, foi possível observar que a precipitação pluviométrica foi equivalente a $14 \%$ da média histórica para o período (Tabela 1), o que pode ter resultado em estresse hídrico e em queda na produção de forragem no experimento. A PMS dos sistemas consorciados também foi baixa, o que pode ser atribuído, além das condições climáticas desfavoráveis, ao fato das forrageiras tropicais, como o capim-braquiária, serem plantas do tipo $\mathrm{C}_{4}$ e exigirem maior quantidade de energia luminosa para seu metabolismo. Nesse sentido,
Castro et al. (1999) com sombreamento artificial de 30 e 60\%, observaram redução de produção de massa seca nas plantas sombreadas. Do mesmo modo, Sousa et al. (2007) também observaram redução na produção de massa seca em pastagem de Brachiaria brizantha sombreada por Zeyheria tuberculosa (bolsa-de-pastor). Estes autores encontraram produção média de 1,2 ton/ha durante o período de dezembro a abril.

Quanto a PMS nos diferentes locais de amostragem, acredita-se que a ausência de efeito significativo seja devida à pequena diferença entre a quantidade de radiação incidente, que foi de 296 e $207 \mu \mathrm{mol} \mathrm{m} \mathrm{m}^{-2} \mathrm{~s}^{-1}$ sob a copa das árvores e na 
entrelinha, respectivamente. Estes resultados não são corroborados pelos de Oliveira et al. (2007a) que observaram maior produção de matéria seca na entrelinha de plantio que na área sombreada.

Não se observou efeito de arranjos, localização e tempo de rebrotação sobre a interceptação luminosa (IL) nos pastos estabelecidos nos dois arranjos espaciais. No entanto, comparando-se descritivamente os diferentes sistemas de produção e ambos os arranjos, nota-se que o sistema em sol pleno apresentou $29 \%$ de IL, enquanto os sistemas em sub-bosque apresentaram 51\% de IL (Tabela 4). Apesar da diferença numérica, a quantidade de radiação interceptada pelas plantas em sol pleno foi de $220 \mu \mathrm{mol} \mathrm{m} \mathrm{m}^{-2} \mathrm{~s}^{-1}$, enquanto a dos arranjos em linhas duplas e simples foi de 99,3 e 153,5, respectivamente. Por meio destes resultados, podese concluir que as plantas em sub-bosque utilizam de mecanismos adaptativos para aumentar a quantidade de luz interceptada em condições limitantes, mesmo apresentando taxa de crescimento reduzida. Segundo Dias-Filho (2000), as principais respostas adaptativas de gramíneas forrageiras tropicais ao sombreamento são o aumento da expansão foliar e redução da área foliar específica, o que as permite manter maior área de folhas mesmo com menor massa de forragem.

Tabela 4. Radiação incidente, radiação interceptada e porcentagem de luz interceptada pelo dossel forrageiro nos diferentes arranjos espaciais.

\begin{tabular}{lccc}
\hline \multirow{2}{*}{ Sistema } & \multicolumn{2}{c}{ Radiação $\left(\mu \mathrm{mol} \mathrm{m}^{-2} \mathrm{~s}^{-1}\right)$} & $\begin{array}{c}\text { Interceptação luminosa } \\
(\%)\end{array}$ \\
\cline { 2 - 3 } & Incidente & Interceptada & 29,0 \\
Convencional & 761,6 & 220,0 & 51,0 \\
Duplo & 194,8 & 99,3 & 51,0 \\
Simples & 301,0 & 153,5 & \\
\hline
\end{tabular}

Fonte: Elaboração dos autores.

Não se observou efeito de espaçamento, local de amostragem e tempo de rebrotação sobre o IAF do pasto. Em sol pleno, as plantas de capimbraquiária exibiram IAF de 2,5, enquanto as plantas dos arranjos apresentaram valor médio de 0,99. Paciullo et al. (2007) observaram IAF de 1,52 em sol pleno e de 0,72 sob $65 \%$ de sombreamento, porém com os mesmos níveis de IL. Esta diferença pode ser atribuída às condições mais favoráveis ao acúmulo de massa seca no sistema em monocultivo de capim-braquiária. Segundo Castro et al. (1999) e Paciullo et al. (2008) o aumento do comprimento da lâmina foliar das plantas cultivadas em SSP também pode ser devido ao aumento da área foliar.

A quantidade de RFAi nos diferentes arranjos espaciais e em sol pleno foi estudada de forma descritiva (Figura 1). A RFAi observada foi de, em média, 194,80; 301,05; e 1005,15 $\mu \mathrm{mol} \mathrm{m} \mathrm{m}^{-2}$ $\mathrm{s}^{-1}$ nos arranjos duplo, simples e em sol pleno, respectivamente. Nota-se também que a quantidade de radiação interceptada pelas árvores foi, na maioria das vezes, maior na entrelinha que sob a copa das árvores, o que pode ser atribuído ao efeito da declinação do sol na época em que o experimento foi conduzido.

A porcentagem de sombreamento ou quantidade de RFA interceptada pelas árvores foi de, em média, $80 \%$ para o arranjo duplo e $70 \%$ para o arranjo simples, nível considerado alto por Paciullo et al. (2007) para B. decumbens. Estes autores afirmaram que níveis de até $35 \%$ não provocam redução na produção de massa seca do capim-braquiária.

Observou-se efeito significativo de interação entre arranjo espacial e local da amostragem para 
quantidade de RFAi $(\mathrm{P}<0,05)$. Na decomposição do efeito de localização dentro de arranjo podese notar que a RFAi sob a copa das árvores foi substancialmente maior que a quantidade incidente na entrelinha do eucalipto (Tabela 5). Esta resposta não era esperada, uma vez que arranjos orientados no sentido leste-oeste tendem a apresentar maior quantidade de luz na entrelinha.

Figura 1. Radiação fotossinteticamente ativa incidente (RFAi) em $\mu$ mol m $\mathrm{m}^{-2} \mathrm{~s}^{-1} \mathrm{e}$ interceptação de luz (IL) pelas árvores nos sistemas com linhas duplas (A) e simples (B) na entrelinha de plantio e sob a copa das árvores.
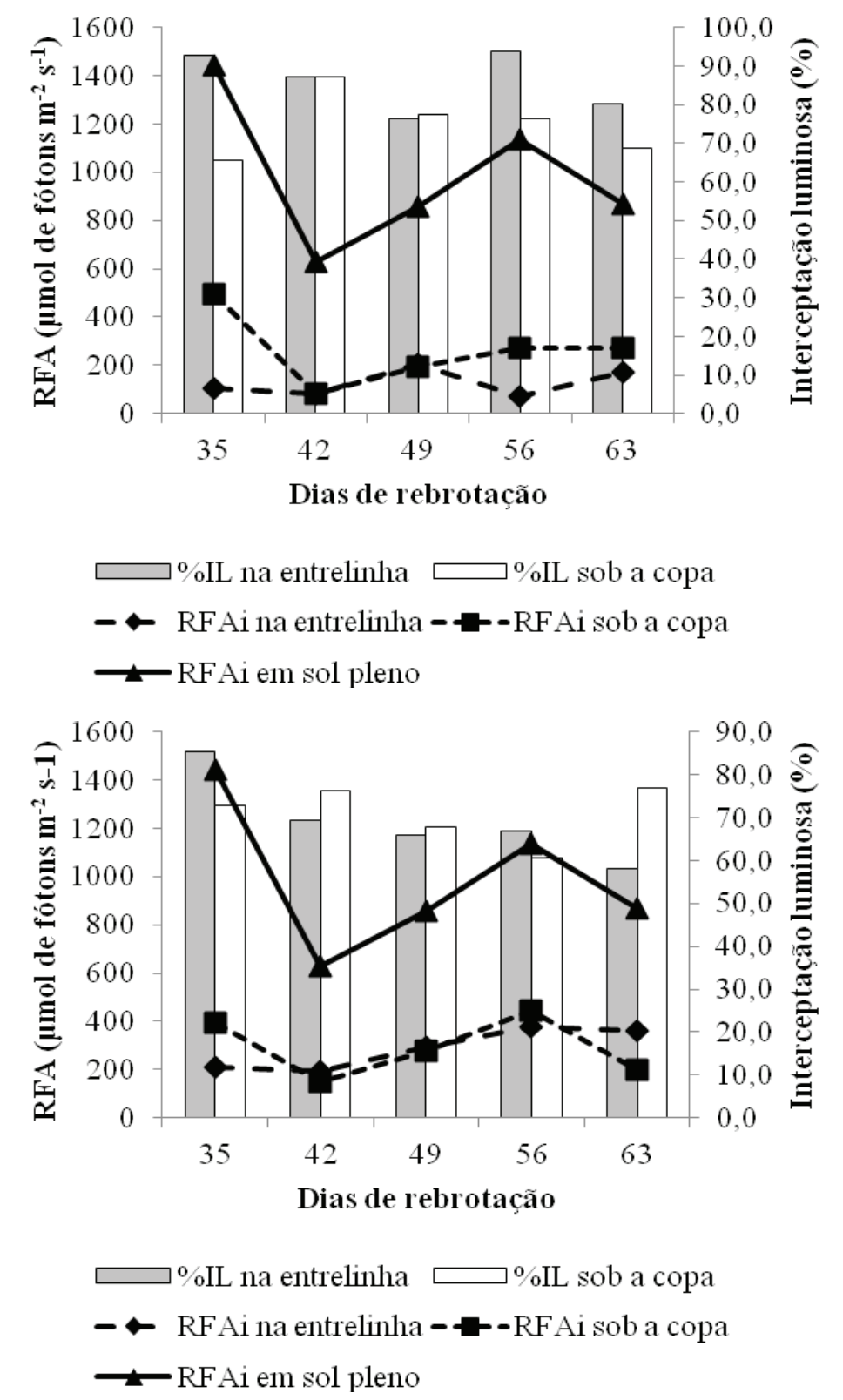

Fonte: Elaboração dos autores. 
Tabela 5. Radiação fotossinteticamente ativa (RFA) $\left(\mu \mathrm{mol} \mathrm{m} \mathrm{m}^{-2} \mathrm{~s}^{-1}\right)$ incidente do desdobramento da interação arranjo espacial do componente arbóreo $\mathrm{x}$ local de amostragem.

\begin{tabular}{lcc}
\hline \multirow{2}{*}{ Local de amostragem } & \multicolumn{2}{c}{ Arranjo } \\
\cline { 2 - 3 } & $(2 \times 2)+9 \mathrm{~m}$ & $9 \times 2 \mathrm{~m}$ \\
\hline Centro da entrelinha & $127,10 \mathrm{~b}$ & $286,90 \mathrm{a}$ \\
Sob copa & $262,50 \mathrm{a}$ & $315,20 \mathrm{a}$ \\
\hline
\end{tabular}

Médias seguidas pela mesma letra, na coluna, não diferem entre si pelo teste de "Tukey" $(\mathrm{P}<0,05)$.

Fonte: Elaboração dos autores.

Provavelmente a realização das avaliações nos meses de abril e maio implicou em variações na declinação solar. Nestes meses o cálculo da declinação solar foi equivalente à $9^{\circ} 47^{\prime} \mathrm{N}$ e $15^{\circ} 81^{\prime}$ $\mathrm{N}$ (VIANELLO; ALVES, 1991) indicando a possibilidade de projeção da sombra na entrelinha do eucalipto. Segundo Andrade et al. (2002), sob estas condições, o sol não se posiciona perpendicular a superfície terrestre, sendo o sombreamento função da altura e arquitetura da copa das árvores, entretanto, estas condições somente são válidas para dias ensolarados onde a luz provém apenas do sol podendo-se subestimar a transmissão de luz em dias nublados (luz difusa).

De fato, durante o período experimental, observou-se que as árvores encontravam-se a uma altura em que sua copa era projetada no centro das entrelinhas de plantio, resultando em maior sombreamento neste local. Resposta semelhante também foi encontrada no estudo de Oliveira et al. (2007b), que observaram nesta mesma área experimental maior densidade de fótons sob a copa das árvores aos 27 meses após o plantio (abril de 2002). Entretanto, de acordo com estes mesmos autores a resposta foi a esperada para sistemas orientados no sentido leste-oeste aos 38 meses após plantio, destacando que esta avaliação foi realizada com declinação solar igual à latitude do local.

Também se observou efeito significativo da interação arranjo $\times$ local de amostragem sobre a relação lâmina:colmo (RLC). No desdobramento da interação observou-se maior RLC nas plantas localizadas no centro da entrelinha em relação à região sob a copa, somente no arranjo duplo (Tabela 6), de modo que a RLC das plantas localizadas no centro da entrelinha foi $13,33 \%$ menor. Esta redução pode ser entendida como uma resposta morfofisiológica das plantas forrageiras para se tornarem mais eficientes na captação de luz em função do maior sombreamento observado na região da entrelinha. Segundo Bernardino e Garcia (2009), as plantas forrageiras possuem capacidade de modificar a estrutura do dossel para adaptar-se a condições sombreadas, sendo tais modificações representadas pelo aumento da relação lâmina:colmo, do comprimento final das folhas e do ângulo foliar, que se torna maior para aumentar a quantidade de luz interceptada por cada folha. Também podem ser citados como modificações estruturais, o aumento do IAF e da área foliar específica, entretanto, não observou-se efeito significativo dos tratamentos, locais e épocas de avaliação sobre o IAF do capimbraquiária.

Tabela 6. Relação lâmina:colmo do capim-braquiária em diferentes arranjos espaciais e em diferentes locais de amostragem.

\begin{tabular}{ccc}
\hline \multirow{2}{*}{ Local de amostragem } & \multicolumn{2}{c}{ Arranjo } \\
\cline { 2 - 3 } & Duplo & Simples \\
\hline Centro da entrelinha & $1,05 \mathrm{a}$ & $1,07 \mathrm{a}$ \\
Sob a copa & $0,91 \mathrm{~b}$ & $1,09 \mathrm{a}$ \\
\hline
\end{tabular}

Médias seguidas pela mesma letra, na coluna, não diferem entre si pelo teste de Tukey $(\mathrm{P}<0,10)$.

Fonte: Elaboração dos autores.

Houve efeito significativo dos intervalos de corte sobre a RLC (Figura 2), de modo que a variação dos dados ajustou-se a um modelo quadrático com aumento inicial da RLC seguido de queda após os 49 dias de rebrotação. Provavelmente o aumento durante os primeiros dias de rebrotação se deve a recuperação da área foliar das plantas após o pastejo. Já a redução é característica de dosséis em 
estágio de desenvolvimento mais avançado, onde o aumento do sombreamento e competição entre as plantas dentro do dossel forrageiro resulta em maior acúmulo de colmos e consequente redução na RLC. De acordo com Van Soest (1994), a RLC deve ser usada como índice de qualidade da forragem, uma vez que o valor nutritivo dos colmos é inferior e a sua presença em grande quantidade no pasto prejudica a apreensão e colheita da forragem pelos animais.

Figura 2. Relação lâmina:colmo em função dos intervalos de corte.

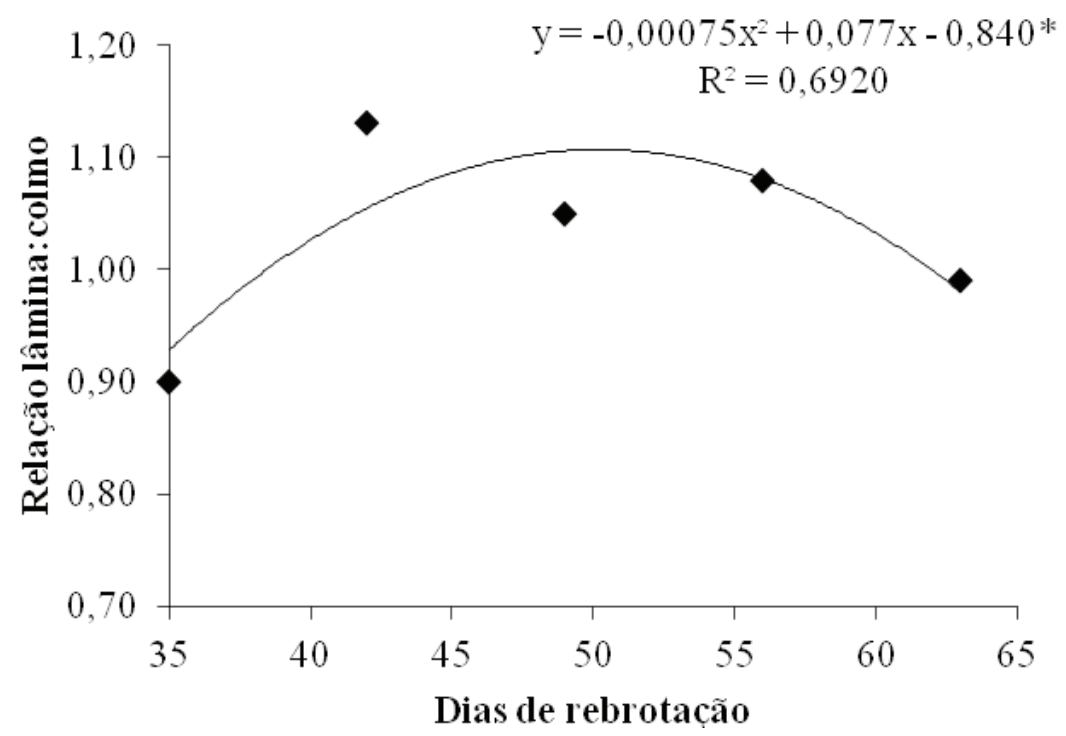

* Significativo a 5\% de probabilidade, pela análise de variância da regressão.

Fonte: Elaboração dos autores.

A altura média do pasto foi de $48 \mathrm{~cm}$ para os arranjos estudados e de de $40 \mathrm{~cm}$ em sol pleno. Martuscello et al. (2009) também observaram aumento da altura da planta com aumento do sombreamento e relataram que plantas sombreadas tendem a aumentar sua área foliar específica se tornando maiores porém menos pesadas não refletindo em maiores produtividades.

Quanto às variáveis de valor nutritivo, teor de matéria seca (MS), proteína bruta (PB), fibra em detergente ácido (FDA) e lignina em ácido sulfúrico (LDA), não observou-se efeito significativo de arranjos espaciais e de local de amostragem, também não foi observado interação entre estas fontes de variação $(\mathrm{P}>0,10)$ (Tabela 7). Os dados de sol pleno foram comparados aos dos arranjos de forma descritiva. Nesse sentido, ambos arranjos e locais de amostragem tiveram teores de MS semelhantes entre si, mas um pouco menores que o do pasto em sol pleno. Resultados semelhantes foram encontrados por Castro et al. (1999) e Sousa et al. (2007) que observaram que o sombreamento implicou em redução no teor de MS.

$\mathrm{O}$ teor de PB também foi semelhante nos diferentes arranjos e locais, mas atingiu valor maior que o observado no pasto em sol pleno. Provavelmente, a redução na taxa de crescimento das plantas sombreadas manteve o teor de PB elevado por mais tempo. Por outro lado, Paciullo et al. (2009) não encontraram efeito do sombreamento nos teores de PB, FDA, e FDN no capim-braquiária em monocultivo e em sistema silvipastoril. Mesmo não havendo efeito significativo dos arranjos, tanto 
em plantas sombreadas com no pasto a sol pleno o teor de PB foi superior ao mínimo necessário para atender as exigências dos micro-organismos ruminais $(7 \% \mathrm{~PB})$ e, sob sombreamento, o teor de PB foi superior a 10\%, mínimo necessário para promover melhor aproveitamento do pasto em regiões tropicais (DETMANN; PAULINO; VALADARES-FILHO, 2010).

Tabela 7. Teores médios de matéria seca (MS), proteína bruta (PB), fibra em detergente neutro (FDN) e lignina em ácido sulfúrico (LAS) do capim-braquiária em dois arranjos espaciais e em dois locais de amostragem.

\begin{tabular}{lccccc}
\hline Arranjo de eucalipto & MS(\%) & PB(\%) & FDN $(\%)$ & FDA $(\%)$ & LAD $(\%)$ \\
\hline Duplo & $27,49 \mathrm{a}$ & $11,21 \mathrm{a}$ & $74,75 \mathrm{a}$ & $42,45 \mathrm{a}$ & $9,00 \mathrm{a}$ \\
Simples & $26,26 \mathrm{a}$ & $10,48 \mathrm{a}$ & $69,25 \mathrm{~b}$ & $38,43 \mathrm{a}$ & $10,00 \mathrm{a}$ \\
\hline Local de amostragem & & & & & \\
Centro da entrelinha & $26,48 \mathrm{a}$ & $10,64 \mathrm{a}$ & $72,07 \mathrm{a}$ & $41,02 \mathrm{a}$ & $10,00 \mathrm{a}$ \\
Sob copa & $27,26 \mathrm{a}$ & $11,04 \mathrm{a}$ & $71,93 \mathrm{a}$ & $39,86 \mathrm{a}$ & $10,00 \mathrm{a}$ \\
\hline Sol pleno & 29,16 & 9,64 & 70,82 & 36,19 & 6,00 \\
\hline
\end{tabular}

Médias seguidas de mesma letra, nas colunas, não diferem entre si pelo teste Tukey $(\mathrm{P}<0,10)$;

Fonte: Elaboração dos autores.

Quanto aos teores de FDA e LAS, Moreira et al. (2009) encontraram valores mais altos em plantas de Brachiaria brizantha sombreadas e atribuíram estes resultados ao aumento na altura do pasto. Provavelmente, a ausência de efeito significativo dos tratamentos, localização e tempo de rebrotação se devem à ocorrência de veranico durante o período experimental. De fato, a ocorrência de períodos não muito prolongados de estresse hídrico pode retardar o processo de desenvolvimento e implicar em manutenção do valor nutritivo.

No presente estudo o teor de FDN foi influenciado pelo tipo de arranjo $(\mathrm{P}<0,10)$, de modo que este foi significativamente maior no arranjo duplo (Tabela 7). Provavelmente, este resultado pode ser devido ao efeito do sombreamento sobre o aumento na produção de colmos em plantas sombreadas. Esta é uma resposta morfofisiológica que as permite posicionar as folhas de modo a maximizar a captação de luz. Entretanto, isso também implica na maior participação de colmos na forragem e consequente aumento no seu teor de parede celular, uma vez que os colmos são tecidos de sustentação e concentram boa parte da fibra das plantas. Segundo Van Soest (1994), o teor de FDN tem grande influência sobre o consumo voluntário e valores superiores a 55-60\% interferem negativamente no consumo de forragem. Sendo assim, a concentração de FDN encontrada neste trabalho esteve acima de tais valores o que provavelmente pode restringir o consumo voluntário de animais em pastejo. Paciullo et al. (2007) observaram menor teor de FDN $(73,1 \%)$ em pastos sombreados do que em sol pleno $(75,9 \%)$, o qual está acima do encontrado no presente trabalho.

A relação entre o intervalo de corte e o teor de matéria seca foi linear e positiva, indicando aumento do teor de matéria seca provavelmente devido ao avanço da maturidade das plantas. Geralmente há um espessamento da parede celular secundária em detrimento do conteúdo celular, ocasionando um incremento no teor de MS (Figura 3) e decréscimo no teor de PB (Figura 4). No entanto, seria esperado um incremento também no teor de FDN, porém não foi observado efeito significativo nos teores de FDN para os intervalos de corte estudados. Este resultado pode ter sido ocasionado pelo efeito do sombreamento que, segundo Paciullo et al. (2007), provoca aumento na taxa de alongamento foliar. Geralmente estas follhas são menos lignificadas, 
contribuindo para diluição do teor de FDN ao longo do tempo. Além disso, segundo Carvalho, Freitas e Xavier (2002), as plantas sombreadas tem sua fase de crescimento alongada, o que pode tornar o processo de espessamento da parede celular mais lento.

Figura 3. Teor de matéria seca para o capim-braquiária em função dos intervalos de corte.

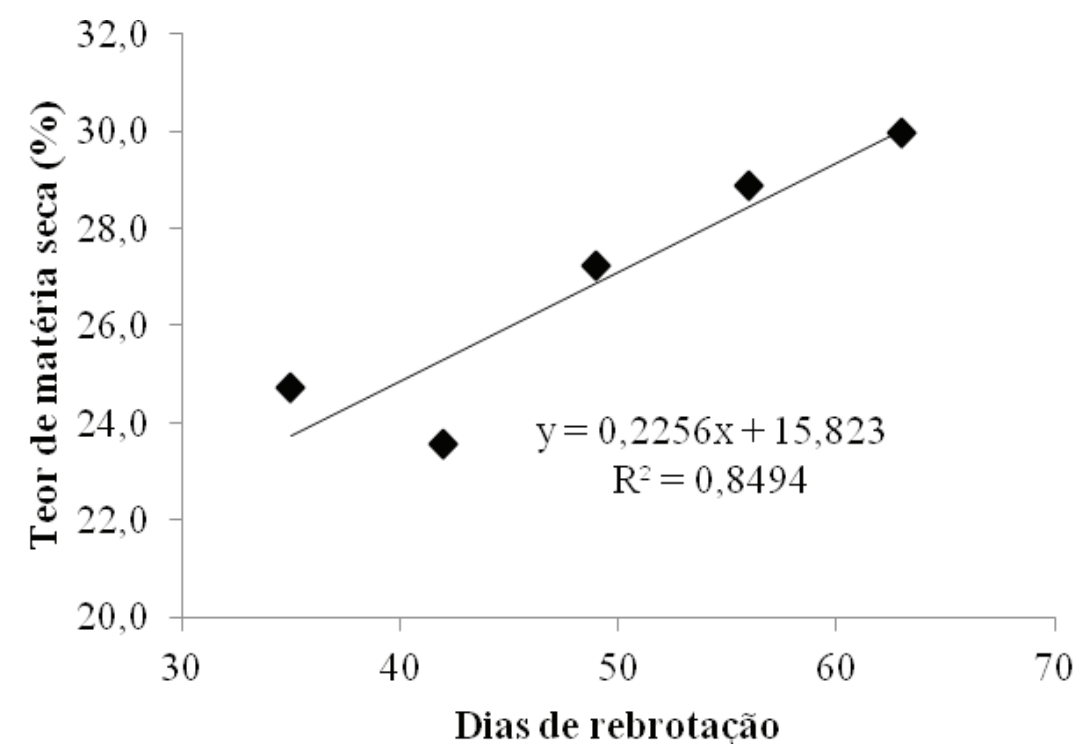

*significativo a 5\% de probabilidade, pela análise de variância da regressão.

Fonte: Elaboração dos autores.

Figura 4. Teor (\%) médio de proteína bruta (PB) do capim-braquiária em função dos intervalos de corte.

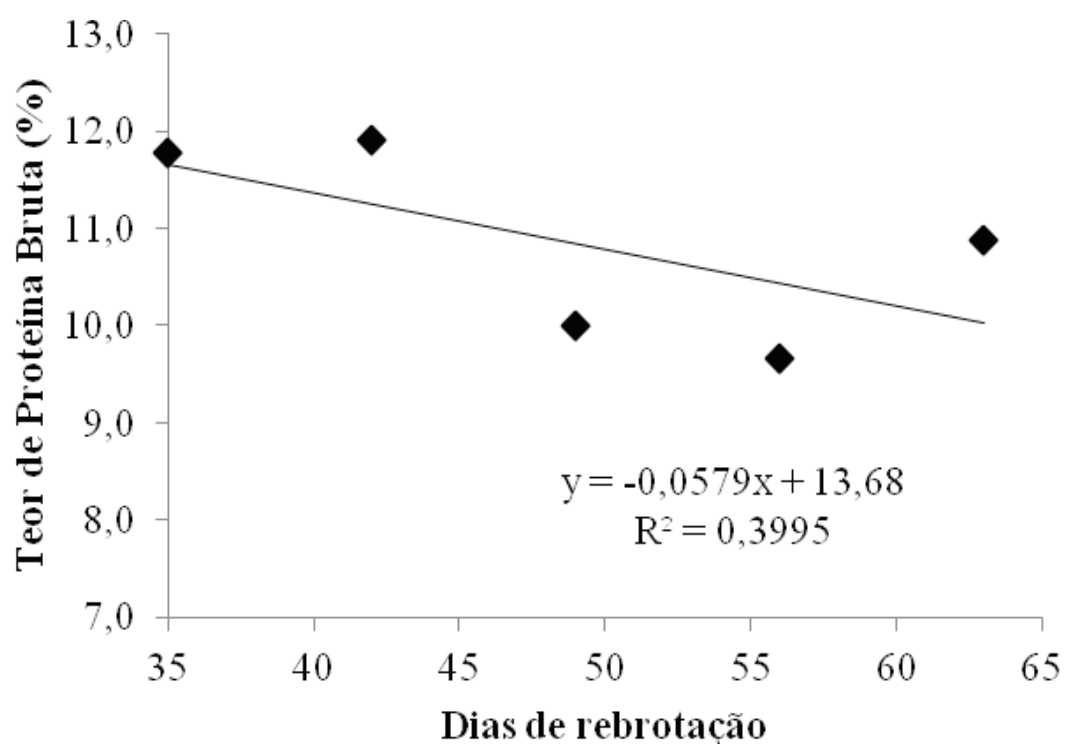

*Significativo a $10 \%$ de probabilidade, pela análise de variância da regressão. Fonte: Elaboração dos autores. 


\section{Conclusões}

O uso de linhas duplas de eucalipto implica em redução na quantidade de radiação incidente no sub-bosque, mas não implica em redução da produtividade do pasto em relação ao arranjo simples. Em sistemas silvipastoris de linhas simples ou duplas, o cultivo do capim-braquiária no centro da entrelinha ou lateral à copa não implica em mudanças na produção e valor nutritivo do mesmo à exceção do teor de fibra em detergente neutro que é maior em arranjos duplos. Estes resultados indicam que o uso de arranjos duplos pode permitir a colheita de maior quantidade de árvores sem prejudicar a produtividade do pasto.

\section{Referências}

ANDRADE, C. M. S.; GARCIA, R.; COUTO, L.; PEREIRA, O. G. Transmissão de Luz em sistemas silvipastoris com eucalipto. Revista Árvore, Viçosa, MG, v. 26, n. 1, p. 19-23, 2002.

BERNARDINO, F. S.; GARCIA, R. Sistemas silvipastoris. Pesquisa Florestal Brasileira, Colombo, v. 60, p. 77-87, 2009. Suplemento Especial.

CARVALHO, M. M.; FREITAS, V. P.; XAVIER, D. F. Início de florescimento, produção e valor nutritivo de gramíneas forrageiras tropicais sob condição de sombreamento natural. Pesquisa Agropecuária Brasileira, Brasília, v. 37, n. 5, p. 717-722, 2002.

CASTRO, C. R. T.; GARCIA, R.; CARVALHO, M. M.; COUTO, L. Produção forrageira de gramíneas cultivadas sob luminosidade reduzida. Revista Brasileira de Zootecnia, Viçosa, MG, v. 28, n. 5, p. 919-927, 1999.

DETMANN, E.; PAULINO, M. F.; VALADARESFILHO, S. C. Otimização dos recursos forrageiros basais. In: SIMPÓSIO DE PRODUÇÃO DE GADO DE CORTE, 7., 2010, Viçosa. Anais... Viçosa: SIMCORTE, 2010. p. 191-240.

DIAS-FILHO, M. B. Growth and biomass allocation of the $\mathrm{C} 4$ grasses Brachiaria brizantha and B. humidicola under shade. Pesquisa Agropecuária Brasileira, Brasília, v. 35, n. 12, p. 2335-2341, 2000.

EMPRESA BRASILEIRA DE PESQUISA AGROPECUÁRIA - EMBRAPA. Centro Nacional de Pesquisa de Solos. Sistema brasileiro de classificação de solos. 2. ed. Rio de Janeiro: EMPBRAPA, 2006. 306 p.
FERREIRA, D. F. SISVAR: um programa para análises e ensino de estatística. Revista Symposium, Lavras, v. 6, n. 2, p. 36-41, 2008.

FOOD AND AGRICULTURE ORGANIZATION OF THE UNITED NATIONS - FAO. Food outlook: global market analysis. 2012. 121 p. Disponível em: <http:// www.fao.org/docrep/015/al989e/al989e00.pdf>. Acesso em: 9 maio 2012.

INSTITUTO BRASILEIRO DE GEOGRAFIA E ESTATÍSTICA - IBGE. Sistema IBGE de recuperação automática. Instituto Brasileiro de Geografia e Estatística, 2012. Disponível em: <http://www.sidra.ibge.gov.br/ $\mathrm{bda} /$ pecua/default.asp? $\mathrm{t}=2 \& \mathrm{z}=\mathrm{t} \& \mathrm{o}=24 \& \mathrm{u} 1=1 \& \mathrm{u} 2=1 \&$ $\mathrm{u} 3=1 \& u 4=1 \& u 5=1 \& u 6=1 \& u 7=1>$. Acesso em: 18 fev. 2014.

MARTUSCELLO, J. A.; JANK , L.; NETO, M. M. G.; LAURA, V. A.; CUNHA, D. N. F. V. Produção de gramíneas do gênero Brachiaria sob níveis de sombreamento. Revista Brasileira de Zootecnia, Viçosa, MG, v. 38, n. 7, p. 1183-1190, 2009.

OLIVEIRA, T. K.; MACEDO, L. G.; SANTOS, I. P. A.; HIGASHIKAWA, E. M.; VENTURIN, N. Produtividade de Brachiaria brizantha (Hochst. Ex A. Rich.) Stapf cv. Marandu sob diferentes arranjos estruturais de sistema agrossilvipastoril com eucalipto. Ciência e Agrotecnologia, Lavras, MG, v. 31, n. 3, p. 748-757, $2007 \mathrm{a}$.

OLIVEIRA, T. K.; MACEDO, R. L. C.; VENTURIN, N.; BOTELHO, S. A.; HIGASHIKAWA, E. M.; MAGALHÃES, W. M. Radiação solar no sub-bosque de sistema agrossilvipastoril com eucalipto em diferentes arranjos estruturais. Cerne, Lavras, v. 13, n. 1, p. 40-50, $2007 b$.

PACIULLO, D. S. C.; CAMPOS, N. R.; GOMIDE, C. A. M.; CASTRO, C. R. T.; TAVELA, R. C.; ROSSIELLO, R. O. P. Crescimento de capim-braquiária influenciado pelo grau de sombreamento e pela estação do ano. Pesquisa Agropecuária Brasileira, Brasília, v. 43, n. 7, p. 917-927, 2008.

PACIULlO, D. S. C.; CARVAlHo, C. A. B.; AROEIRA, L. J. M.; MORENZ, M. J. F.; LOPES, F. C. F.; ROSSIELLO, R. O. P. Morfofisiologia e valor nutritivo do capim-braquiária sob sombreamento natural e a sol pleno. Pesquisa Agropecuária Brasileira, Brasília, v. 42, n. 4, p. 573-579, 2007.

PACIULLO, D. S. C.; LOPES, F. C. F.; MALAQUIAS JUNIOR, J. D.; VIANA FILHO, A.; RODRIGUEZ, N. M.; MORENZ, M. J. F.; AROEIRA, L. J. M. Características do pasto e desempenho de novilhas em sistema silvipastoril e pastagem de braquiária 
em monocultivo. Pesquisa Agropecuária Brasileira, Brasília, v. 44, n. 11, p. 1528-1535, 2009.

SILVA, D. J.; QUEIROZ, A. C. Análise de alimentos: métodos químicos e biológicos. 3. ed. Viçosa: Editora UFV, 2002. $235 \mathrm{p}$.

SOARES, A. B.; SARTOR, L. R.; PAULO, F. A.; VARELLA, A. C.; MEZZALIRA, J. C. Influência da luminosidade no comportamento de onze espécies forrageiras perene de verão. Revista Brasileira de Zootecnia, Viçosa, MG, v. 38, n. 3, p. 443-451, 2009.
SOUSA, L. F.; MAURÍCIO, R. M.; GONÇALVES, L. C.; SALIBA, E. O. S.; MOREIRA, G. R. Produtividade e valor nutritivo da Brachiaria brizantha $\mathrm{cv}$. Marandu em um sistema silvipastoril. Arquivo Brasileiro de Medicina Veterinária e Zootecnia, Belo Horizonte, v. 59, n. 4, p. 1029-1037, 2007.

VAN SOEST, P. J. Nutritional ecology of the ruminant. 2. ed. Ithaca: Cornell University, 1994. 476 p.

VIANELLO, R. L.; ALVES, A. R. Meteorologia básica e aplicações. Viçosa: Universidade Federal de Viçosa, Imprensa Universitária, 1991. 449 p. 
